\title{
Coronary endothelial function in patients with obstructive sleep apnea
}

\author{
Andrew Cassar ${ }^{\mathrm{a}}$, Timothy I. Morgenthaler ${ }^{\mathrm{b}}$, Charanjit S. Rihal ${ }^{\mathrm{a}}$, Abhiram Prasad $^{\mathrm{a}}$, Ryan J. \\ Lennon ${ }^{\mathrm{c}}$, Lilach O. Lerman ${ }^{\mathrm{a}, \mathrm{d}}$, and Amir Lerman ${ }^{\mathrm{a}}$ \\ aDepartment of Internal Medicine, Division of Cardiovascular Diseases, Mayo Clinic, Rochester, \\ Minnesota, USA \\ ${ }^{b}$ Department of Internal Medicine, Division of Pulmonary and Critical Care, Mayo Clinic, \\ Rochester, Minnesota, USA \\ 'Department of Health Sciences Research, Division of Biomedical Statistics and Informatics, \\ Mayo Clinic, Rochester, Minnesota, USA \\ dDepartment of Internal Medicine, Division of Nephrology and Hypertension, Mayo Clinic, \\ Rochester, Minnesota, USA
}

\section{Abstract}

Objective-Obstructive sleep apnea (OSA) has been associated with increased risk for cardiovascular events, possibly mediated by endothelial dysfunction. The current study evaluates the association between invasive coronary endothelial dysfunction and OSA in patients with nonobstructive coronary atherosclerosis.

\begin{abstract}
Methods-All patients who had undergone both polysomnography and an invasive coronary vasomotor study at the Mayo Clinic, Rochester, Minnesota, from January 1997 to August 2011 were identified ( $n=143)$. OSA was defined as an apnea-hypopnea index of 5 or higher. Three endpoints of coronary endothelial function - percentage change in coronary artery diameter at the mid and distal left anterior descending artery to intracoronary acetylcholine and percentage change in coronary blood flow to intracoronary acetylcholine - were assessed. Differences between patients with OSA $(n=102)$ and those without OSA $(n=41)$ were evaluated using multivariate analysis of variance. Follow-up mortality data were collected and Kaplan-Meier curves were plotted to evaluate differences in mortality between patients with and without OSA.
\end{abstract}

Results-Patients with OSA were more likely to have hypertension compared with patients without OSA. OSA was not significantly associated with coronary endothelial dysfunction on univariate analysis $(P=0.23)$ and after adjustment for hypertension $(P=0.19)$. Similarly, there was no significant difference in coronary endothelial function in patients who had oxygen desaturation of less than $90 \%$ during polysomnography $(P=0.42)$. There was a trend toward

(C) 2013 Wolters Kluwer Health | Lippincott Williams \& Wilkins

Correspondence to Amir Lerman, MD, Department of Internal Medicine, Division of Cardiovascular Disease, Mayo Clinic, 200 First Street SW, Rochester, MN 55905, USA, Tel: + 1507 255 4152; fax: + 1507255 2550; lerman.amir@mayo.edu.

Conflicts of interest

There are no conflicts of interest. 
higher mortality in patients with OSA compared with those without OSA, but this did not reach statistical significance ( 5 vs. $0 \%$ at 10 years, $P=0.25$ ).

Conclusion-The current study suggests that OSA is not an independent risk factor for coronary endothelial dysfunction in patients with early coronary atherosclerosis. Adverse coronary outcomes in patients with OSA may be independent of coronary endothelial dysfunction. Coron

\section{Keywords}

acetylcholine; coronary artery diameter; coronary blood flow; coronary risk factor; endothelial dysfunction; obstructive sleep apnea

\section{Introduction}

Sleep disordered breathing affects $\sim 24 \%$ of men and $9 \%$ of women between the ages of 30 and 60 years [1], and obstructive sleep apnea (OSA) has been associated with a 70\% relative increased risk of cardiovascular morbidity and mortality [2,3]. Endothelial dysfunction is associated with the pathogenesis and clinical course of atherosclerosis [4,5] and a four-fold increased risk for cardiovascular events [6-8]. Several studies have shown that OSA is associated with endothelial dysfunction in peripheral vessels [9-11]. Other studies associated OSA with endothelial dysfunction by demonstrating increased levels of inflammatory markers [12-14] and reduced levels of nitric oxide [15]. It has been hypothesized that the increased risk for cardiovascular events in patients with OSA might be mediated by endothelial vasomotor dysfunction [16]. To address this hypothesis we examined the association of OSA with invasively determined coronary endothelial dysfunction.

\section{Methods}

\section{Study design, study population, and data collection}

After approval by the Mayo Clinic Institutional Review Board, all patients who had undergone polysomnography at the Mayo Clinic, Rochester, Minnesota, from January 1997 to August 2011 were identified. This database of 51360 patients was cross-referenced with the coronary physiology and imaging database at the Mayo Clinic to identify those patients who had also undergone an invasive coronary vasomotor study $(n=143)$. Four patients had undergone more than one invasive coronary vasomotor evaluation test, and only the earliest test was included in the analysis. Eleven patients had undergone polysomnography twice only the polysomnogram in closest temporal relation with the coronary vasomotor assessment test was included in the study. The median time between the two tests was 20.3 months (interquartile range 0.03-59.1). Forty-three patients had undergone the two tests within 6 months of each other. The medical records were reviewed by one investigator and the patient characteristics, risk factors, laboratory values, medications, polysomnography data, and coronary vasomotor study details were recorded. We divided the patients into two groups according to the presence $(n=102)$ or absence $(n=41)$ of OSA. OSA was defined as an apnea-hypopnea index of 5 or higher on polysomnography [17]. Forty-six of the 102 patients with OSA had moderate to severe OSA (apnea-hypopnea index 215 ). We tested for 
a difference in coronary endothelial function endpoints between patients with OSA and those without OSA (Fig. 1).

Coronary vasomotor studies were conducted for clinical indications, typically chest pain syndrome with no or mild epicardial coronary artery disease. Exclusion criteria for carrying out invasive coronary vasomotor assessments at our institution include a history of ischemic heart disease (myocardial infarction, percutaneous coronary revascularization, coronary artery bypass grafting, unstable angina), angiographic coronary artery lesions of greater than $40 \%$ luminal diameter stenosis, heart failure with an ejection fraction less than $40 \%$, valvular heart disease, stroke, or significant hepatic, renal, or inflammatory disease within 6 months of the invasive study. Pregnant or lactating patients were excluded. Patients who required treatment with positive inotropic agents other than digoxin during the study were excluded. Long-acting nitrates or calcium-channel blockers were withheld for 36-48 h before the study to allow assessment of baseline coronary physiology. Diagnostic coronary angiography and invasive endothelial function assessment was performed as previously described [8,18]. In brief, a Doppler guide-wire (FloWire; Volcano Corp., Rancho Cordova, California, USA) within a coronary infusion catheter was positioned in the midportion of the left anterior descending coronary artery. Average peak velocity (APV) was obtained from Doppler flow velocity spectra [19]. Coronary artery diameter (DIA) measurements were made in the mid left anterior descending artery segment $5 \mathrm{~mm}$ distal to the tip of the Doppler and in the distal left anterior descending artery using an online quantitative coronary angiography program (Medis Corporation, Leiden, The Netherlands) [20]. Analysis of data from our laboratory shows that the intraobserver variability is $6 \pm 5$ and $2.0 \pm 2.4 \%$ for the DIA and APV, respectively [8,21]. Assessment of coronary endothelial function was performed by selective infusion of increasing concentrations of acetylcholine $\left(10^{-6}, 10^{-5}\right.$, and $10^{-4} \mathrm{~mol} / \mathrm{l}$ ) at $1 \mathrm{ml} / \mathrm{min}$ at $3 \mathrm{~min}$ intervals with Doppler measurements and coronary angiography after each infusion. The relative changes in DIA at the mid and distal left anterior descending artery and in APV to intracoronary acetylcholine were calculated. Coronary blood flow $(\mathrm{CBF})$ was determined from the equation:

$$
C B F=\pi(A P V / 2)(D I A / 2)^{2} .
$$

We also collected follow-up mortality data from the Mayo registration records $(n=141)$ to determine whether there was a difference in mortality between patients with and those without OSA. Further, a questionnaire was sent to patients to determine major adverse cardiac and cerebrovascular events (MACCE) including death, myocardial infarction, coronary artery bypass grafting, percutaneous coronary intervention, or stroke $(n=50)$.

\section{Statistical analysis}

We carried out a power analysis for a pooled two-sample $t$-test using the above sample size. Using a type 1 error of 0.0167 (to keep an overall error rate of 0.05 for three endpoints) and pooled SD of 25 for percent change in DIA (from our data), we had $99 \%$ power to detect a $20 \%$ difference in DIA at both the mid and distal left anterior descending artery between patients with and those without OSA. 
Continuous variables are summarized as mean $\pm \mathrm{SD}$ and compared between patients with and those without OSA using Student's $t$-test. Categorical variables are presented as frequency (group percentage) and compared using Pearson's $\chi^{2}$-test. Three endpoints of coronary endothelial function (\% change in mid left anterior descending artery DIA to acetylcholine, $\%$ change in distal left anterior descending artery DIA to acetylcholine, and \% change in CBF to acetylcholine) were specified. To test whether there was any difference in endpoints between patients with and those without OSA, multivariate analysis of variance was carried out. If the overall comparison of the endpoint means was significant (according to Wilks' $\lambda$ statistic), then individual endpoint tests were inspected to see which means were different. Covariates that were significantly different between the two groups were included for covariance adjustment. Variables screened for inclusion included age, sex, BMI, smoking status, hypertension, diabetes, hyperlipidemia, depression, total cholesterol, high-density lipoprotein cholesterol, low-density lipoprotein cholesterol, triglycerides, serum creatinine, glucose, high-sensitivity $\mathrm{C}$-reactive protein, aspirin use, $\beta$-blocker use, lipid-lowering drug use, antihypertensive use, and insulin use. Only hypertension was significantly different and thus included as a model covariate. $P$-values less than 0.05 were considered statistically significant. Kaplan-Meier curves were plotted for follow-up data for mortality and MACCE from the time of polysomnography. SAS version 9.2 (SAS Institute, Cary, North Carolina, USA) was used for all analyses.

\section{Results}

The baseline patient characteristics of those with and those without OSA are shown in Table 1. Patients with OSA were significantly more likely to have hypertension; otherwise, the two groups were similar in terms of age, sex, smoking history, diabetes mellitus, hyperlipidemia, and use of aspirin, lipid-lowering drugs, and antihypertensive agents. Testing for coronary endothelial function revealed that the relative change in DIA (at both the mid and distal left anterior descending artery segments) and CBF in response to acetylcholine in patients with OSA was not significantly worse compared with that in patients without OSA (Table 1). OSA was not significantly associated with coronary endothelial dysfunction on univariate analysis $(P=0.23$; Fig. 2$)$ or after adjustment for hypertension $(P=0.19)$. Similarly, coronary endothelial function was not worse in patients who had oxygen desaturation of less than $90 \%$ for at least $10 \%$ of sleep time during polysomnography $(P=0.42)$. A test for interaction yielded no evidence $(P=0.26)$ of the association between OSA and coronary endothelial function being different between men and women. In addition, there was no significant correlation between moderate-severe OSA [defined as an apnea-hypopnea index of 15 or higher $(n=46)]$ and coronary endothelial dysfunction $(P=0.10)$. Coronary endothelial response was not different between the 12 patients who were on treatment for OSA [and were compliant with their continuous positive airway pressure (CPAP) for at least 6 weeks] before the cardiac catheterization and the remainder of the OSA group $(P=0.90)$. Even if these treated patients are excluded from the OSA group, there is still no difference in association between OSA and coronary endothelial function [multivariate analysis of variance $P=0.35$ (unadjusted) and $P=0.32$ (adjusted)]. If only the patients who had undergone polysomnography within 6 months of their coronary endothelial function test were considered ( $n=43$, OSA $n=30$, without OSA $n=13$ ), OSA was not significantly 
associated with coronary endothelial dysfunction on univariate analysis $(P=0.12)$ or after adjustment for hypertension $(P=0.15)$. Testing for coronary endothelium-independent function with coronary flow reserve to adenosine revealed that patients with OSA did not have a statistically significantly worse coronary flow reserve in response to adenosine when compared with patients without OSA $(P=0.93$; Table 1$)$.

Follow-up data on mortality and MACCE from the time of polysomnography are shown in Figs 3 and 4. All patients without OSA were alive after 10 years of follow-up. Even though there was a trend toward worse survival in patients with OSA, there was no statistically significant difference in mortality between patients with OSA and those without OSA. Similarly, there was no statistically significant difference in MACCE between patients with OSA and those without OSA.

\section{Discussion}

To our knowledge, the current study is the first to use invasively determined parameters for coronary endothelial dysfunction in humans to assess independent risk for OSA for endothelial dysfunction. The study suggests that in patients with early coronary atherosclerosis, OSA is not an independent risk factor for coronary endothelial dysfunction and that both of these risk factors may contribute independently to cardiovascular events in humans.

Previous studies have suggested OSA may be associated with endothelial dysfunction in patients with early coronary atherosclerosis and that OSA may induce endothelial dysfunction, resulting in an increased propensity for cardiovascular events [16]. However, our study found no correlation between OSA or hypoxemia and coronary endothelial dysfunction. The pathogenesis of increased cardiovascular risk in patients with OSA remains incompletely understood but is likely to be multifactorial. A diverse range of mechanisms including sympathetic nervous system overactivity, selective activation of inflammatory molecular pathways, abnormal coagulation, and metabolic dysregulation (particularly involving insulin resistance and disordered lipid metabolism) [22] may be more important than coronary endothelial dysfunction in increasing the risk for coronary artery disease in patients with OSA. These systemic changes in patients with OSA may be more prominent in the peripheral vasculature [23-25] than in the coronary vascular tree. Increased sympathetic activity in OSA leads to systemic hypertension [23], which is a well-known risk factor for endothelial dysfunction and coronary artery disease. Indeed, the association of OSA with flow-mediated brachial blood flow in response to cuff occlusion [26] or sodium nitroprusside administration [24] is stronger in patients with OSA and combined hypertension. In the present study, patients with OSA had increased prevalence of hypertension and there was a trend toward higher likelihood to be treated with $\beta$-blockers compared with patients without OSA. The use of $\beta$-blockers in the patients with OSA might have attenuated the increased sympathetic response and thus possibly the pathogenesis for worse coronary endothelial dysfunction [27].

OSA may increase myocardial events because of acute hemodynamic local effects on coronary plaques at night rather than chronic inflammatory effects on endothelial function. 
Nocturnal hypoxemia results in sympathetic activation and surges in blood pressure, which may lead to plaque rupture, coronary thrombosis, and myocardial infarction [28,29]. It is possible that the increased sympathetic activity in OSA may result in increased cardiovascular events by increasing heart failure [30] and arrhythmias [31-33] rather than coronary endothelial dysfunction and coronary artery disease. A recent paper casts further doubt on OSA being an additional independent risk factor for the incidence of coronary artery disease [30].

It is possible that there is no direct cause and effect between OSA and coronary endothelial dysfunction but that they often coexist in patients with multiple risk factors. Multiple confounding factors may be responsible for endothelial dysfunction in patients with OSA. Such confounding factors include obesity [34,35], chronic obstructive pulmonary disease [36,37], and hypertension [23], which have been associated with increased inflammatory markers, cardiovascular events, and endothelial dysfunction. In the Sleep Heart Health study [26], which is the only large study to date, OSA was associated with peripheral endothelial dysfunction (measured by brachial artery flow-mediated dilatation) on univariate analysis but was not an independent predictor of endothelial dysfunction after adjustment for obesity (except in patients with hypertension after subgroup analysis).

Circulating endothelial cells and endothelial progenitor cells are novel surrogate markers of endothelial damage and repair, respectively. A most recent study [38] showed that coexistent mild-to-moderate sleep disordered breathing in patients with acute myocardial infarction increased the mobilization, proliferative, and angiogenic capacities of endothelial progenitor cells, angiogenic T-cell numbers, and vascular endothelial growth factor expression in monocytes compared with patients without sleep disordered breathing. Further, induced hypoxemia in vitro had similar effects on healthy endothelial progenitor cell functions. This confirmed earlier findings [39,40], which showed no difference in circulating endothelial cells or endothelial progenitor cells in patients with sleep apnea versus patients with hypertension or healthy controls. Further, there was no difference in circulating endothelial cells or endothelial progenitor cells after CPAP treatment. This further supports the possibility that OSA is not an independent cause of endothelial dysfunction.

Limitations of our study include its retrospective nature with possible selection bias as the patients included were referred for coronary angiography with vasomotor testing because of symptoms. This may be the reason for inclusion of a control group with coronary endothelial dysfunction due to a relatively high prevalence of traditional risk factors (smoking, hypertension, hyperlipidemia, and diabetes) known to be associated with endothelial dysfunction. This may have made independent further worsening in coronary endothelial function because of OSA less likely. Conversely, the advantage of having a control group with significant risk factors is that most patients in the general population with OSA (as in our study patients with OSA) also have a high prevalence of these risk factors [23,30] and our aim was to study whether OSA is an independent further risk for coronary endothelial dysfunction in patients with early atherosclerosis. However, it may not be possible to extrapolate the data from this study cohort to patients with OSA without other significant risk factors for coronary artery disease. Our study has several strengths: (i) the assessment of 
endothelial dysfunction in patients with OSA was performed for the first time in the coronary vasculature rather than relying on peripheral surrogates such as brachial ultrasound or systemic inflammatory markers, and (ii) previous studies showing an association of OSA with endothelial dysfunction were small (<50 patients) [9-11,40] making our study much larger and less prone to a type II error due to chance. A large randomized prospective trial to test the hypothesis that OSA is associated with coronary endothelial dysfunction would be ideal. This would involve enrolling asymptomatic patients to undergo both polysomnography and an invasive coronary endothelial function test and then comparing endothelial function in patients with and those without OSA. Further, it would be of interest to treat patients with OSA with CPAP and then to reperform a coronary endothelial function test to see whether there is an improvement in endothelial function with treatment.

\section{Conclusion}

The current study suggests that OSA is not independently associated with coronary endothelial dysfunction in patients with early coronary atherosclerosis. Thus, adverse coronary outcomes in patients with OSA may be indirect and independent of coronary endothelial dysfunction, and assessment for both conditions may be additive to risk stratification among patients with early coronary atherosclerosis.

\section{Acknowledgments}

The authors thank Becky E. Nelson for study coordination and Jonella M. Tilford and Teresa L. Jarland for their valuable help in collecting the data for the coronary physiology and imaging database. This study was supported by the National Institute of Health (NIH Grants AG004875, AG031750, HL64924, HL085307, DK77013, DK73608, and HL77131) and the Mayo Foundation.

\section{References}

1. Young T, Palta M, Dempsey J, Skatrud J, Weber S, Badr S. The occurrence of sleep-disordered breathing among middle-aged adults. N Engl J Med. 1993; 328:1230-1235. [PubMed: 8464434]

2. Mooe T, Franklin KA, Holmstrom K, Rabben T, Wiklund U. Sleep-disordered breathing and coronary artery disease: long-term prognosis. Am J Respir Crit Care Med. 2001; 164:1910-1913. [PubMed: 11734445]

3. Peker Y, Carlson J, Hedner J. Increased incidence of coronary artery disease in sleep apnoea: a long-term follow-up. Eur Respir J. 2006; 28:596-602. [PubMed: 16641120]

4. Fuster V, Badimon L, Badimon JJ, Chesebro JH. The pathogenesis of coronary artery disease and the acute coronary syndromes. N Engl J Med. 1992; 326:242-250. [PubMed: 1727977]

5. Ross R. Atherosclerosis - an inflammatory disease. N Engl J Med. 1999; 340:115-126. [PubMed: 9887164]

6. Schachinger V, Britten MB, Zeiher AM. Prognostic impact of coronary vasodilator dysfunction on adverse long-term outcome of coronary heart disease. Circulation. 2000; 101:1899-1906. [PubMed: 10779454]

7. Lerman A, Zeiher AM. Endothelial function: cardiac events. Circulation. 2005; 111:363-368. [PubMed: 15668353]

8. Suwaidi JA, Hamasaki S, Higano ST, Nishimura RA, Holmes DR Jr, Lerman A. Long-term followup of patients with mild coronary artery disease and endothelial dysfunction. Circulation. 2000; 101:948-954. [PubMed: 10704159]

9. Ip MS, Tse HF, Lam B, Tsang KW, Lam WK. Endothelial function in obstructive sleep apnea and response to treatment. Am J Respir Crit Care Med. 2004; 169:348-353. [PubMed: 14551167] 
10. Lattimore JL, Wilcox I, Skilton M, Langenfeld M, Celermajer DS. Treatment of obstructive sleep apnoea leads to improved microvascular endothelial function in the systemic circulation. Thorax. 2006; 61:491-495. [PubMed: 16537671]

11. Kato M, Roberts-Thomson P, Phillips BG, Haynes WG, Winnicki M, Accurso V, et al. Impairment of endothelium-dependent vasodilation of resistance vessels in patients with obstructive sleep apnea. Circulation. 2000; 102:2607-2610. [PubMed: 11085964]

12. Ohga E, Nagase T, Tomita T, Teramoto S, Matsuse T, Katayama H, et al. Increased levels of circulating ICAM-1, VCAM-1, and L-selectin in obstructive sleep apnea syndrome. J Appl Physiol. 1999; 87:10-14. [PubMed: 10409552]

13. Yokoe T, Minoguchi K, Matsuo H, Oda N, Minoguchi H, Yoshino G, et al. Elevated levels of Creactive protein and interleukin- 6 in patients with obstructive sleep apnea syndrome are decreased by nasal continuous positive airway pressure. Circulation. 2003; 107:1129-1134. [PubMed: 12615790]

14. Shamsuzzaman AS, Winnicki M, Lanfranchi P, Wolk R, Kara T, Accurso V, et al. Elevated Creactive protein in patients with obstructive sleep apnea. Circulation. 2002; 105:2462-2464. [PubMed: 12034649]

15. Ip MS, Lam B, Chan LY, Zheng L, Tsang KW, Fung PC, et al. Circulating nitric oxide is suppressed in obstructive sleep apnea and is reversed by nasal continuous positive airway pressure. Am J Respir Crit Care Med. 2000; 162:2166-2171. [PubMed: 11112132]

16. Ryan S, Taylor CT, McNicholas WT. Systemic inflammation: a key factor in the pathogenesis of cardiovascular complications in obstructive sleep apnoea syndrome? Thorax. 2009; 64:631-636. [PubMed: 19561283]

17. Sleep-related breathing disorders in adults: recommendations for syndrome definition and measurement techniques in clinical research. The Report of an American Academy of Sleep Medicine Task Force. Sleep. 1999; 22:667-689. No authors listed. [PubMed: 10450601]

18. Cassar A, Chareonthaitawee P, Rihal CS, Prasad A, Lennon RJ, Lerman LO, et al. Lack of correlation between noninvasive stress tests and invasive coronary vasomotor dysfunction in patients with nonobstructive coronary artery disease. Circ Cardiovasc Interv. 2009; 2:237-244. [PubMed: 20031721]

19. Doucette JW, Corl PD, Payne HM, Flynn AE, Goto M, Nassi M, et al. Validation of a Doppler guide wire for intravascular measurement of coronary artery flow velocity. Circulation. 1992; 85:1899-1911. [PubMed: 1572046]

20. Reiber JH, Serruys PW, Kooijman CJ, Wijns W, Slager CJ, Gerbrands JJ, et al. Assessment of short-, medium-, and long-term variations in arterial dimensions from computer-assisted quantitation of coronary cineangiograms. Circulation. 1985; 71:280-288. [PubMed: 3965172]

21. Nishimura RA, Lerman A, Chesebro JH, Ilstrup DM, Hodge DO, Higano ST, et al. Epicardial vasomotor responses to acetylcholine are not predicted by coronary atherosclerosis as assessed by intracoronary ultrasound. J Am Coll Cardiol. 1995; 26:41-49. [PubMed: 7797774]

22. McNicholas WT, Bonsigore MR. Sleep apnoea as an independent risk factor for cardiovascular disease: current evidence, basic mechanisms and research priorities. Eur Respir J. 2007; 29:156178. [PubMed: 17197482]

23. Nieto FJ, Young TB, Lind BK, Shahar E, Samet JM, Redline S, et al. Sleep Heart Health Study. Association of sleep-disordered breathing, sleep apnea, and hypertension in a large communitybased study. Jama. 2000; 283:1829-1836. [PubMed: 10770144]

24. Carlson JT, Rangemark C, Hedner JA. Attenuated endothelium-dependent vascular relaxation in patients with sleep apnoea. J Hypertens. 1996; 14:577-584. [PubMed: 8762200]

25. Kraiczi H, Caidahl K, Samuelsson A, Peker Y, Hedner J. Impairment of vascular endothelial function and left ventricular filling: association with the severity of apnea-induced hypoxemia during sleep. Chest. 2001; 119:1085-1091. [PubMed: 11296174]

26. Nieto FJ, Herrington DM, Redline S, Benjamin EJ, Robbins JA. Sleep apnea and markers of vascular endothelial function in a large community sample of older adults. Am J Respir Crit Care Med. 2004; 169:354-360. [PubMed: 14551166] 
27. Kraiczi H, Hedner J, Peker Y, Grote L. Comparison of atenolol, amlodipine, enalapril, hydrochlorothiazide, and losartan for antihypertensive treatment in patients with obstructive sleep apnea. Am J Respir Crit Care Med. 2000; 161:1423-1428. [PubMed: 10806134]

28. Kuniyoshi FH, Garcia-Touchard A, Gami AS, Romero-Corral A, van der Walt C, Pusalavidyasagar S, et al. Day-night variation of acute myocardial infarction in obstructive sleep apnea. J Am Coll Cardiol. 2008; 52:343-346. [PubMed: 18652941]

29. Kohler M, Stradling JR. Mechanisms of vascular damage in obstructive sleep apnea. Nat Rev Cardiol. 2010; 7:677-685. [PubMed: 21079639]

30. Gottlieb DJ, Yenokyan G, Newman AB, O'Connor GT, Punjabi NM, Quan SF, et al. Prospective study of obstructive sleep apnea and incident coronary heart disease and heart failure: the sleep heart health study. Circulation. 2010; 122:352-360. [PubMed: 20625114]

31. Cassar A, Morgenthaler TI, Lennon RJ, Rihal CS, Lerman A. Treatment of obstructive sleep apnea is associated with decreased cardiac death after percutaneous coronary intervention. J Am Coll Cardiol. 2007; 50:1310-1314. [PubMed: 17903628]

32. Gami AS, Pressman G, Caples SM, Kanagala R, Gard JJ, Davison DE, et al. Association of atrial fibrillation and obstructive sleep apnea. Circulation. 2004; 110:364-367. [PubMed: 15249509]

33. Gami AS, Howard DE, Olson EJ, Somers VK. Day-night pattern of sudden death in obstructive sleep apnea. N Engl J Med. 2005; 352:1206-1214. [PubMed: 15788497]

34. Ryan S, Nolan GM, Hannigan E, Cunningham S, Taylor C, McNicholas WT. Cardiovascular risk markers in obstructive sleep apnoea syndrome and correlation with obesity. Thorax. 2007; 62:509514. [PubMed: 17251313]

35. Al Suwaidi J, Higano ST, Holmes DR Jr, Lennon R, Lerman A. Obesity is independently associated with coronary endothelial dysfunction in patients with normal or mildly diseased coronary arteries. J Am Coll Cardiol. 2001; 37:1523-1528. [PubMed: 11345360]

36. Moro L, Pedone C, Scarlata S, Malafarina V, Fimognari F, Antonelli-Incalzi R. Endothelial dysfunction in chronic obstructive pulmonary disease. Angiology. 2008; 59:357-364. [PubMed: 18388072]

37. Eickhoff P, Valipour A, Kiss D, Schreder M, Cekici L, Geyer K, et al. Determinants of systemic vascular function in patients with stable chronic obstructive pulmonary disease. Am J Respir Crit Care Med. 2008; 178:1211-1218. [PubMed: 18836149]

38. Berger S, Aronson D, Lavie P, Lavie L. Endothelial progenitor cells in acute myocardial infarction and sleep-disordered breathing. Am J Respir Crit Care Med. 2013; 187:90-98. [PubMed: 23155141]

39. Martin K, Stanchina M, Kouttab N, Harrington EO, Rounds S. Circulating endothelial cells and endothelial progenitor cells in obstructive sleep apnea. Lung. 2008; 186:145-150. [PubMed: 18401642]

40. Butt M, Khair OA, Dwivedi G, Shantsila A, Shantsila E, Lip GY. Myocardial perfusion by myocardial contrast echocardiography and endothelial dysfunction in obstructive sleep apnea. Hypertension. 2011; 58:417-424. [PubMed: 21747042] 


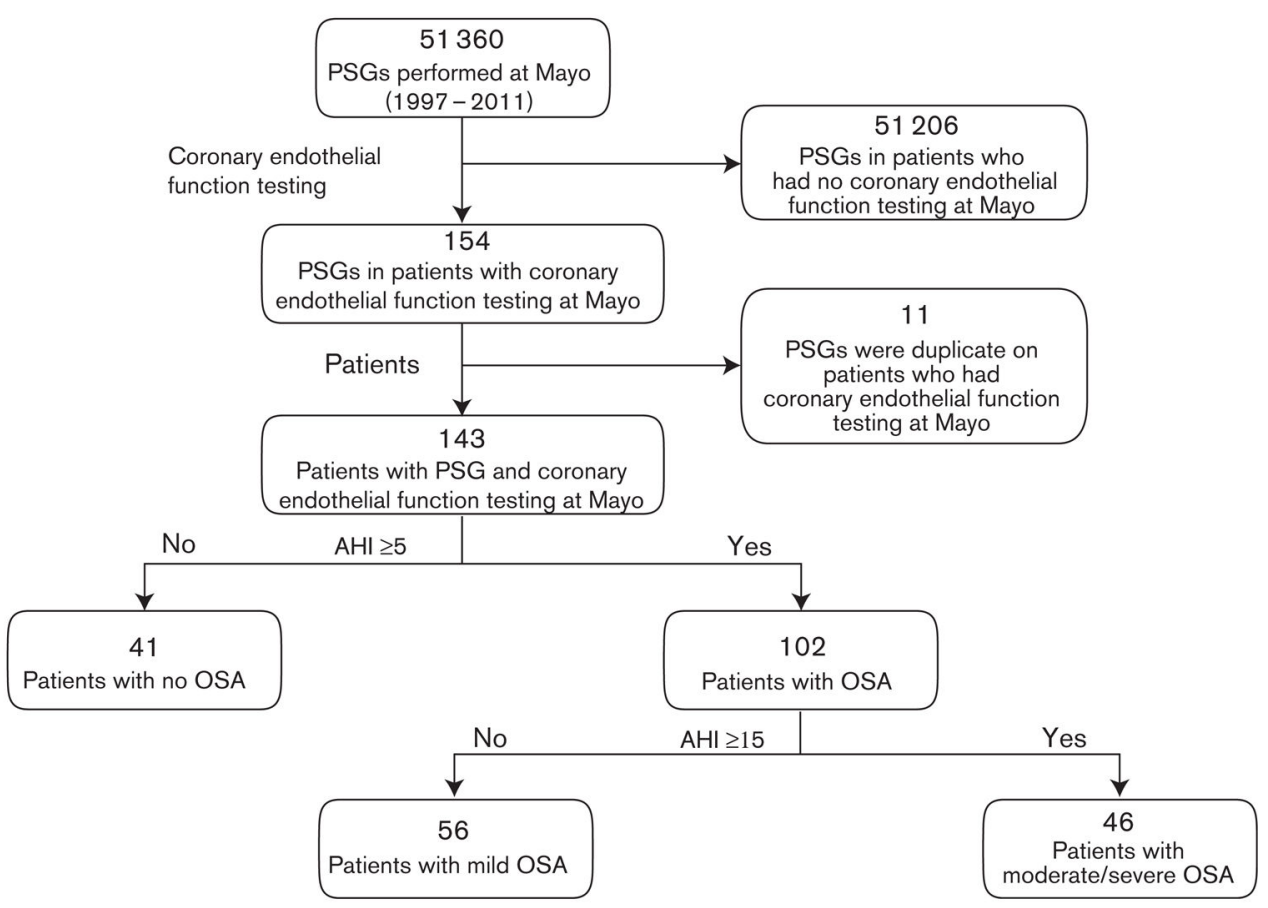

Fig. 1.

Study cohort profile. AHI, apnea-hypopnea index; OSA, obstructive sleep apnea; PSG, polysomnography. 

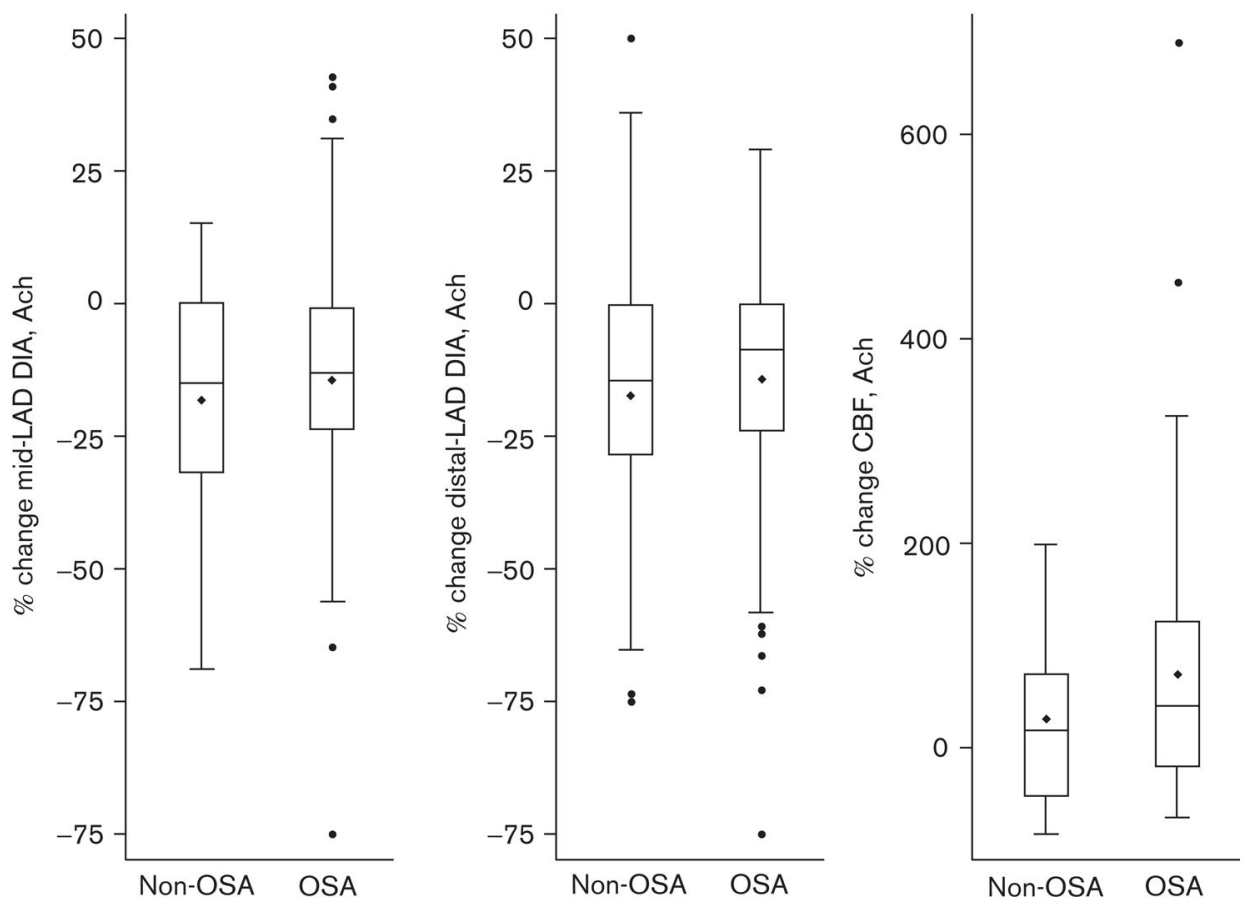

Fig. 2.

Coronary artery diameter at the mid and distal LAD and coronary blood flow response to acetylcholine in patients with OSA versus those without OSA. \%chg., percentage change; Ach, acetylcholine; CBF, coronary blood flow; DIA, coronary artery diameter; LAD, left anterior descending artery; OSA, obstructive sleep apnea. 


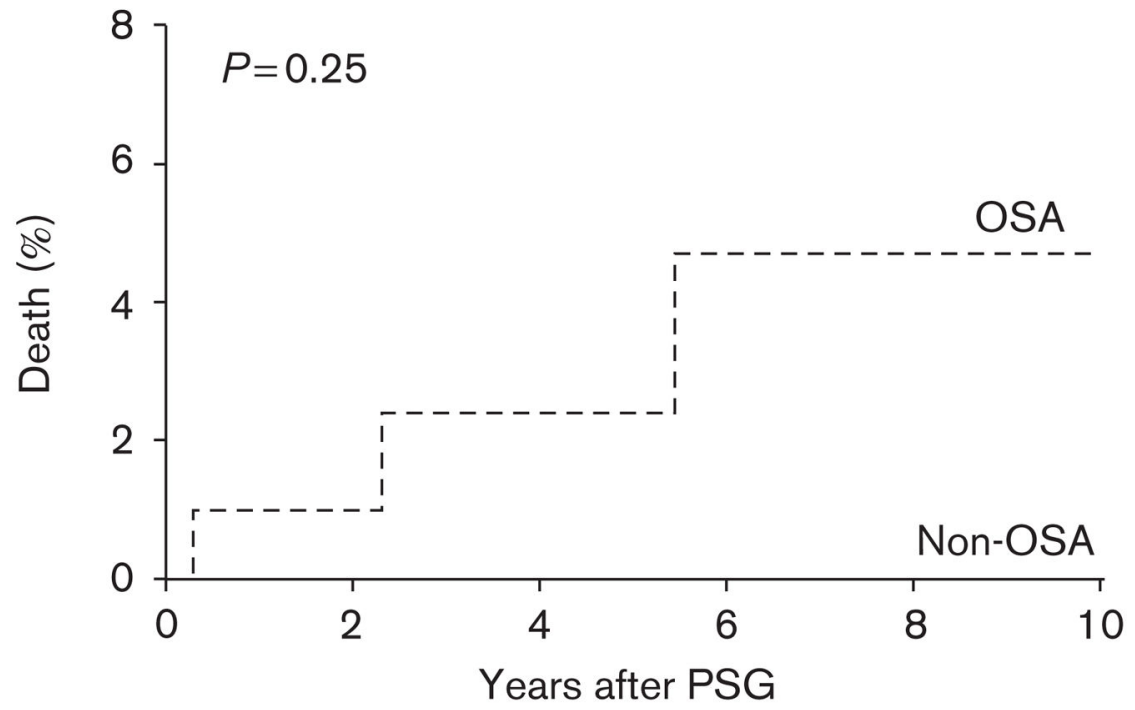

$\begin{array}{llllllllllll}\text { Non-OSA } & 40 & 35 & 33 & 28 & 23 & 20 & 16 & 13 & 11 & 7 & 2\end{array}$ $\begin{array}{llllllllllll}\text { OSA } & 101 & 87 & 75 & 66 & 52 & 49 & 38 & 33 & 24 & 17 & 15\end{array}$

Fig. 3.

Kaplan-Meier curve for mortality after PSG in patients with and without OSA. OSA, obstructive sleep apnea; PSG, polysomnography. 


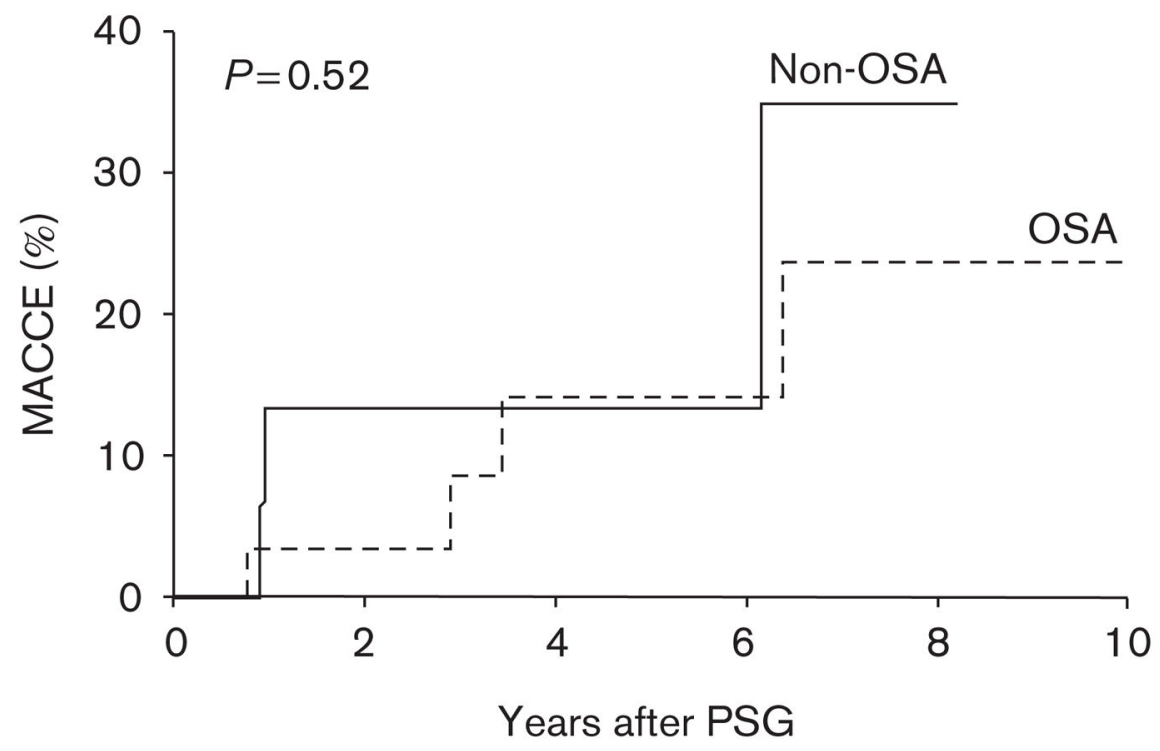

$\begin{array}{llllllllllll}\text { Non-OSA } & 15 & 13 & 13 & 9 & 7 & 6 & 4 & 3 & 2 & 0 & 0 \\ \text { OSA } & 35 & 28 & 22 & 18 & 15 & 14 & 10 & 7 & 5 & 4 & 3\end{array}$

Fig. 4.

Kaplan-Meier curve for MACCE after PSG in patients with and those without OSA. MACCE, major adverse cardiac and cerebrovascular events; OSA, obstructive sleep apnea; PSG, polysomnography. 
Table 1

Patient characteristics and results

\begin{tabular}{|c|c|c|c|}
\hline Variables & Non-OSA $(n=41)$ & OSA $(n=102)$ & $P$-value \\
\hline Age (years) & $47.2 \pm 9.3$ & $50.4 \pm 13.4$ & 0.16 \\
\hline $\operatorname{Men}[n(\%)]$ & $10(24)$ & $36(35)$ & 0.21 \\
\hline BMI & $32.3 \pm 7.4$ & $33.2 \pm 6.9$ & 0.51 \\
\hline Apnea-hypopnea index [median (Q1, Q3)] & $2(1,3)$ & $13(8,27)$ & \\
\hline$<90 \%$ time with Sat $>90 \%[n(\%)]$ & $1(2)$ & $27(28)$ & $<0.001$ \\
\hline Smoking status $[n(\%)]$ & & & 0.47 \\
\hline Never smoked & $20(49)$ & $43(42)$ & \\
\hline Former smoker & $16(39)$ & $44(43)$ & \\
\hline Current smoker & $5(12)$ & $15(15)$ & \\
\hline Hypertension $[n(\%)]$ & $12(29)$ & $60(59)$ & 0.001 \\
\hline Diabetes $[n(\%)]$ & $4(10)$ & $14(14)$ & 0.52 \\
\hline Hyperlipidemia $[n(\%)]$ & $24(59)$ & $74(73)$ & 0.10 \\
\hline Creatinine $(\mathrm{mg} / \mathrm{dl})$ & $0.9(0.2)$ & $1.0(0.5)$ & 0.33 \\
\hline Depression $[n(\%)]$ & $18(44)$ & $31(31)$ & 0.16 \\
\hline $\operatorname{hsCRP}(\mathrm{mg} / \mathrm{l})$ & $2.4 \pm 4.3$ & $3.1 \pm 6.0$ & 0.54 \\
\hline Aspirin use $[n(\%)]$ & $17(41)$ & $53(52)$ & 0.26 \\
\hline$\beta$-Blocker use $[n(\%)]$ & $9(22)$ & $35(34)$ & 0.15 \\
\hline Lipid-lowering drug use $[n(\%)]$ & $13(32)$ & $44(43)$ & 0.21 \\
\hline Antihypertensive use $[n(\%)]$ & $10(24)$ & $26(25)$ & 0.89 \\
\hline Baseline heart rate & $73.3 \pm 12.6$ & $71.6 \pm 14.4$ & 0.53 \\
\hline Baseline mean arterial pressure & $98.1 \pm 9.9$ & $100.4 \pm 13.6$ & 0.36 \\
\hline$\%$ change $\mathrm{CBF}, \mathrm{Ach}$ & $28.0 \pm 76.5$ & $70.7 \pm 120.9$ & 0.041 \\
\hline$\%$ change mid-LAD DIA, Ach & $-18.5 \pm 21.5$ & $-14.5 \pm 22.7$ & 0.34 \\
\hline$\%$ change distal LAD DIA, Ach & $-16.7 \pm 26.9$ & $-14.5 \pm 21.3$ & 0.60 \\
\hline CFR & $3.1 \pm 0.7$ & $3.1 \pm 0.9$ & 0.93 \\
\hline$\%$ change $\mathrm{CBF} \leq 50 \%[n(\%)]$ & $26(65)$ & $50(51)$ & 0.13 \\
\hline$\%$ change mid-LAD DIA $\leq 20 \%[n(\%)]$ & $17(41)$ & $31(31)$ & 0.23 \\
\hline $\operatorname{Max}$ CFR $\leq 2.5[n(\%)]$ & $8(20)$ & $30(29)$ & 0.23 \\
\hline Peripheral arterial tonometry, reactive hyperemia index & $1.9 \pm 0.4$ & $1.7 \pm 0.5$ & 0.33 \\
\hline
\end{tabular}

Ach, acetylcholine; CBF, coronary blood flow; CFR, coronary flow reserve ratio; DIA, coronary artery diameter; hsCRP, high-sensitivity Creactive protein; $\mathrm{LAD}$, left anterior descending artery; OSA, obstructive sleep apnea; Sat, saturation. 